\title{
BRCA1 loss pre-existing in small subpopulations of prostate cancer is associated with advanced disease and metastatic spread to lymph nodes and peripheral blood
}

\author{
Natalia Bednarz ${ }^{1,3}$, Elke Eltze ${ }^{4}$, Axel Semjonow ${ }^{5}$, Michael Rink ${ }^{2}$, Antje Andreas ${ }^{1}$, Lennart \\ Mulder $^{6}$, Juliane Hannemann ${ }^{1}$, Margit Fisch ${ }^{2}$, Klaus Pantel ${ }^{1}$, Heinz-Ulrich G. Weier ${ }^{7}$, \\ Krzysztof P. Bielawski ${ }^{3}$, and Burkhard Brandt ${ }^{1}$ \\ ${ }^{1}$ Institute of Tumor Biology, University Medical Center Hamburg-Eppendorf, Hamburg, Germany \\ 2 Department of Urology, University Medical Center Hamburg-Eppendorf, Hamburg, Germany ${ }^{3}$ \\ Molecular Diagnostics Division, Intercollegiate Faculty of Biotechnology, University of Gdansk \\ and Medical University of Gdansk, Gdansk, Poland ${ }^{4}$ Institute of Pathology, University of Münster, \\ Münster, Germany ${ }^{5}$ Department of Urology, University of Münster, Münster, Germany 6 \\ Department of Experimental Therapy, The Netherlands Cancer Institute, Amsterdam, The \\ Netherlands ${ }^{7}$ Life Sciences Division, University of California, E.O. Lawrence Berkeley National \\ Laboratory, Berkeley, USA
}

\begin{abstract}
Purpose-A preliminary study performed on a small cohort of multifocal prostate cancer ( $\mathrm{PCa})$ detected BRCA1 allelic imbalances (AI) among circulating tumor cells (CTCs). The present analysis was aimed to elucidate the biological and clinical role of BRCA1 losses on metastatic spread and tumor progression in prostate cancer patients.
\end{abstract}

Experimental Design-To map molecular progression in PCa outgrowth we used FISH analysis of tissue microarrays (TMA), lymph node sections and CTC from peripheral blood.

Results-We found that $14 \%$ of 133 tested patients carried monoallelic BRCA1 loss in at least one tumor focus. Extended molecular analysis of chr17q revealed that this aberration was often a part of larger cytogenetic rearrangement involving chr17q21 accompanied by AI of the tumor suppressor gene PTEN and lack of the BRCA1 promoter methylation. The BRCA1 losses correlated with advanced T stage ( $\mathrm{p}<0.05)$, invasion to pelvic lymph nodes (LN, $\mathrm{p}<0.05$ ) as well as BR ( $\mathrm{p}<0.01)$. Their prevalence was twice as high within $62 \mathrm{LN}$ metastases (LNMs) as in primary tumors $(27 \%, \mathrm{p}<0.01)$. The analysis of 11 matched primary $\mathrm{PCa}-\mathrm{LNM}$ pairs confirmed the suspected transmission of genetic abnormalities between those two sites. In 4 of 7 patients with metastatic disease, BRCA1 losses appeared in a minute fraction of cytokeratin- and vimentinpositive CTCs.

Conclusions-Small subpopulations of PCa cells bearing BRCA1 losses might be one confounding factor initiating tumor dissemination and might provide an early indicator of shortened disease-free survival.

Corresponding author. Burkhard Brandt, Institute of Tumor Biology, University Medical Center Hamburg-Eppendorf, Martinistr. 52, 20246 Hamburg, Germany; phone +49-40-7410-57495 fax +49-40-7410-56546 bu.brandt@uke.uni-hamburg.de. 


\section{Keywords}

prostate cancer; dissemination; BRCA1 loss; biochemical recurrence; circulating tumor cells; cytogenetics; FISH

\section{Introduction}

Prostate cancer $(\mathrm{PCa})$ is one of the most frequent types of tumors in high-income countries. Its frequently observed multifocality (ca. $80 \%$ of cases) and biological heterogeneity hamper significantly both diagnosis and treatment. It is believed that only a certain subpopulation of cancer cells is related to $\mathrm{PCa}$ aggressiveness and accounts for its progression. Therefore, a relevant diagnostic tool defining a subclone of invasive cells is urgently required. A recent study showed that standard serum prostate specific antigen (PSA)-based screening is beneficial for reducing the lethality of $\mathrm{PCa}$, but is also associated with a high risk of 'overdiagnosis' (1). On the other hand, some PCa patients who suffer from organ confined tumors and have negative bone scans succumb to distant metastases after complete tumor resection. It is reasonable to assume that those tumors had gained the ability of migration, disseminate to regional lymph nodes (LNs) and even bones long before the overt manifestation of metastases. Thus, one promising approach to the early identification of patients at high risk of $\mathrm{PCa}$ metastasis is determination of molecular signatures of primary foci associated with lymph node metastasis (LNM) and/or biochemical recurrence (BR) and subsequent detection of circulating tumor cells (CTCs) (2).

In a previous profiling study based on allelic imbalances (AI) analysis of CTCs isolated from peripheral blood of PCa patients and a small cohort of corresponding primary tumor foci, AIs of 9 loci were observed in a fraction of CTCs. Intriguing, the BRCA1 AI was found in four of five cases where BR occurred within three years after a prostatectomy (3). It was hypothesized that haploinsufficiency of the BRCA1 gene in even a small subclone of tumor cells is associated with the occurrence of CTCs in the patients' peripheral blood as well as early $\mathrm{BR}$ of $\mathrm{PCa}$ and hence might account for metastasis formation.

The BRCA1 protein acts as a prominent tumor suppressor and due to its 'canonical', but yet largely unknown functions in cell cycle regulation and homologous recombination, is a key player in cellular control systems (4). The clinical relevance of BRCA1 alterations is welldocumented in both hereditary and sporadic breast and ovarian cancers (5). However, BRCA1 deficiency or AIs were also observed in some other types of tumors (6-8) and corresponded to a worsened survival $(6,7)$. The germline BRCA1 mutations were already reported to indicate a higher risk of PCa and its more aggressive phenotype (9-11). BRCA1 AIs were also detected in approx. 13-46\% of tested cases of sporadic PCa (12-15). They coincided frequently with the AIs of other loci on chr17q21 and, to the best of our knowledge, only in one study were associated with the higher PCa stage (14). These AI analyses were conducted on the very low number of cases (23-25 samples) and did not exclude the possibility that alterations of another tumor suppressor gene located on $17 \mathrm{q} 21$ can play a pivotal role in prostate tumorigenesis.

Therefore, the aim of this study was to investigate whether distinct BRCA1 alterations or larger rearrangements of chr17q12-21 may serve as a potential signature of progression in sporadic PCa. The BRCA1 gene locus, a gene rich region located on 17q21 proximal of the BRCA1 gene (17q GRR) and ERBB-2/HER-2 were analysed in primary tumors, lymph nodes and CTCs and compared to the clinical staging, grading, and outcome. 


\section{Materials and Methods}

\section{Patients}

The patients with sporadic mono- and multifocal PCa were treated by radical prostatectomy in the Department of Urology of University of Muenster during 1998-2000. They did not receive any hormone therapy and did not manifest any metastasis at the time point of diagnosis and surgery. The tumors were characterized by different clinical parameters (Tab. 1). Their pathologic stages ranged from $\mathrm{T} 2 \mathrm{~N} 0 \mathrm{M} 0$ to $\mathrm{T} 3 \mathrm{~N} 1 \mathrm{M} 0$ and the final Gleason sums from 2 to 10 . The mean patient age at the moment of surgery was 64 years old (range: 47 78). The concentration of serum PSA was measured after prostatectomy twice every year and occurrence of BR was defined as the end-point of disease-free survival. The follow-up was available for 186 patients with a median follow-up of 34 months (range: 1-114). Additionally, seven patients with metastatic PCa treated at the Department of Urology, University Medical Centre, Hamburg-Eppendorf, Germany were selected for CTCs analysis. Their short clinical description is embedded in Fig. 3B.

\section{Clinical samples}

Two tissue microarrays (TMA) containing 398 primary PCa and 196 LNM tissue cores (TCs), corresponding to 199 and 98 patients, respectively, were prepared as described (16). $53(13 \%)$ TCs contained normal prostate tissue, further 337 (85\%) tumor TCs belonged to 191 (96\%) patients, 8 TCs were missing pathologic characteristics. All specimens were evaluated by a pathologist in the Institute of Pathology, University of Münster, Germany. The patients with multifocal PCa were represented on the TMA by TCs originated from two different tumor foci. From this cohort, 31 cases of primary tumors were selected for additional AI analysis and 11 paired PCa-LNM formalin-fixed, paraffin-embedded (FFPE) tissues were chosen for both FISH and AI analyses.

At the Department of Urology, University Medical Centre, Hamburg-Eppendorf, Germany, $20 \mathrm{ml}$ of peripheral blood from seven unrelated patients with metastatic $\mathrm{PCa}$ and three healthy volunteers was collected into EDTA tubes and processed for CTC enrichment within three hours after phlebotomy as described (17).

\section{FISH}

FISH probes were prepared from DNA isolated from BAC clones RP11-242D8 and RP11-506G7 using a Large DNA Construct Isolation Kit (Qiagen, Germany) and the BioPrime ${ }^{\circledR}$ Total Genomic Labeling System (GibcoInvitrogen, UK) according to the manufacturers' protocols. The deparaffinized 4- $\mu \mathrm{m}$-thick TMA or FFPE sections were fixed in $2 \%$ formaldehyde in methanol for $10 \mathrm{~min}$ at $-20^{\circ} \mathrm{C}$ and pretreated in Spot-Light Tissue Heat Pretreatment Buffer (Zymed) for $10 \mathrm{~min}$ at $97^{\circ} \mathrm{C}$. The cells were digested for $10 \mathrm{~min}$ in $100 \mu \mathrm{l}$ Enzyme-Buffer (Zymed) at $37^{\circ} \mathrm{C}$ and subsequently dehydrated in a graded alcohol series. One microliter of COT1 ${ }^{\mathrm{TM}}$ Human DNA (Roche, Germany), $1 \mu \mathrm{l}$ of CEP17 Spectrum Aqua ${ }^{\circledR}$ (Abbott Molecular) as a reference probe and $4 \mu \mathrm{l}$ of Spectrum Orange ${ }^{\circledR}$-labeled probe (Abbott Molecular) for a target gene suspended in $4 \mu$ of hybridization buffer ( $20 \%$ dextran sulfate $/ 50 \%$ formamide $/ 4 \times \mathrm{SSC}$ buffer) were applied on the top of specimens. For ERBB-2/HER-2 detection, $10 \mu \mathrm{l}$ of commercial ready-to-use probe (PathVysionTM Her-2 DNA Probe Kit, Abbott Molecular) was used. The specimens were denatured for $3 \mathrm{~min}$ at $95^{\circ} \mathrm{C}$ and hybridized for at least 16 hours at $37^{\circ} \mathrm{C}$. Afterwards, they were washed 2 min each in $2 \times \mathrm{SSC} / \mathrm{NP}-40$ buffer at $72^{\circ} \mathrm{C}$ and at $21^{\circ} \mathrm{C}$. The specimens were dehydrated in an alcohol series, counterstained with Vectashield ${ }^{\circledR}$ Mounting Medium (Vector Laboratories Inc., Burlingame, CA) containing $0.5 \mu \mathrm{g} / \mathrm{ml}$ 4',6-diamidino-2-phenylindole (DAPI) and analyzed in a fluorescence microscope (Zeiss, Germany). For each tissue core, target and reference probe signals were counted in at least 20 cells showing a minimum of two signals for the 
reference probe. The gene dosage calculated as ratio of the number of target probe signal over reference probe signals was determined according to experimental cut-offs established on 20 normal prostate tissues for every probe combination.

\section{FISH on CTCs}

Isolated CTCs on slides were fixed in ice-cold $75 \%$ ethanol for 2 min then pretreated with $100 \mu \mathrm{g} / \mathrm{ml} \mathrm{RNase}$ A for $40 \mathrm{~min}$ at $21^{\circ} \mathrm{C}$, before cells were immersed in $1 \mathrm{x}$ citrate buffer ( $\mathrm{pH}$ 6.0, Dako, Denmark) for $3 \mathrm{~min}$ at $120^{\circ} \mathrm{C}$. The cells were postfixed in $1 \%$ formaldehyde in $1 \times$ PBS for $10 \mathrm{~min}$, and dehydrated in an alcohol series. Air-dried cells were denatured in denaturation buffer ( $70 \%$ formamide, $0.6 \times \mathrm{SSC}, \mathrm{pH} 7.4$ ) for $5 \mathrm{~min}$ at $73^{\circ} \mathrm{C}$ and dehydrated in alcohol. Hybridization was conducted as described above with minor modifications $(2 \mu \mathrm{lof}$ Spectrum Orange ${ }^{\circledR}$-labelled RP11-242D8 probe, $0.5 \mu$ l CEP17, $6.5 \mu$ l hybridization buffer, Abbott Molecular). The next day, the slides were washed three times for $10 \mathrm{~min}$ in $50 \%$ formamide $/ 2 \times \mathrm{SSC}$ buffer, two times for $10 \mathrm{~min}$. in $2 \times \mathrm{SSC}$ buffer and once for $5 \mathrm{~min}$ in $0.1 \times \mathrm{SSC} / 0.1 \%$ Tween- 20 buffer at $46^{\circ} \mathrm{C}$. The cells were permeabilized in three changes of $1 \times$ Tris Buffered Saline/1\% Tween-20 (TBST) for 3 min. each. The unspecific binding was reduced by a 20 min incubation in Blocking Serum (Dako). The primary mouse monoclonal antibodies against pan-cytokeratin (A45, Mikromet, Germany) or vimentin (RV202, DB Pharmingen ${ }^{\mathrm{TM}}$ ) diluted 1:100 or 1:200, respectively, in DakoREAL ${ }^{\mathrm{TM}}$ Antibody Diluent (Dako) were applied to the cells for $45 \mathrm{~min}$ at $21^{\circ} \mathrm{C}$. The specimens were washed three times for 3 min with 1×TBST and incubated with a secondary 1:200-diluted Alexa-488-labeled anti-mouse rabbit antibody (MiBioTech) for $45 \mathrm{~min}$ at $21^{\circ} \mathrm{C}$. Finally, the slides were washed twice for 3 min with $1 \times$ TBST and once for 3 min with $1 \times \mathrm{PBS}$, and counterstained with Vectashield ${ }^{\circledR}$ Mounting Medium containing DAPI. Cytokeratin- or vimentin-positive cells, showing no apoptotic or necrotic morphology, were analyzed for their BRCA1 gene dosage. Additionally, a total of 500 cells per sample were scored for BRCA1 losses and compared to the scores obtained in three healthy volunteers (false-hybridization index).

\section{Al analysis \\ DNA isolation, microsatellite-sequence-based PCR and AI analysis of locus D17S855 \\ (BRCA1) and D10S541 (PTEN) were performed as described (3).}

\section{Methylation assay}

To investigate the BRCA1 promoter methylation status, a MLPA-assay, described in (18), was performed (Methylation Kit ME45, MRC-Holland, The Netherlands) according to the manufacturer's protocol with minor modifications (initial denaturation for $20 \mathrm{~min}, 40$ PCR cycles). Data were normalized by Methylation Status Analysis and further analyzed by the Coffalyser MLPA data analysis software.

\section{Statistics}

Kruskal-Wallis and Mann-Whitney tests were performed to assess genes dosages associations with clinical outcome. To estimate the hazard risk, Cox-Hazard-Potential regression analysis (CI 95\%) was done. Disease free survival curves were generated by Kaplan-Meier test with log-rank univariate analysis.

\section{Results}

\section{Experimental strategy}

To test the hypothesis that BRCA1 gene aberrations in PCa may be decisive events in primary $\mathrm{PCa}$ progression, our retrospective study investigated their frequency in primary PCa, LNM and CTCs isolated from peripheral blood of metastatic PCa patients. The 
samples flow is presented in Tab. S1. In order to assess specificity, efficiency and accuracy of the selected FISH probes, 20 normal prostate tissues and different prostate and breast cancer cell lines were tested. The experimental cut-offs for normal gene dosage were calculated as $0.71-1.29,0.72-1.28$ and $0.80-1.20$ for BRCA1, 17q GRR and ERBB-2/ HER-2, respectively.

\section{BRCA1 gene dosage in primary prostate cancers}

Two-hundred-thirteen TCs from 133 PCa patients were evaluable for FISH analysis of the BRCA1 gene (Fig. 1A-B). BRCA1 losses and gains occurred in $18(14 \%)$ and $5(7 \%)$ of patients, respectively. The BRCA1 gene dosage obtained by FISH agreed with BRCA1 AI status assessed in a subgroup of 31 selected tumors $\left(R^{2}=0.614, p<0.001\right.$, Fig. S1). Eightyone tested patients $(62 \%)$ were investigated in two TCs which enabled the assessment of heterogeneity of BRCA1 gene dosage within the analyzed PCa. Eighty-three percent of the BRCA1 aberrations were observed only in one TC which suggested the unique character of these alterations confined to the small population of tumor cells.

\section{Characterization of BRCA1 aberrations and their clinical relevance}

All detected BRCA1 losses were monoallelic and appeared in majority of tumor cells localized in single TC (containing usually 20 to 1000 tumor cells). Promoter analysis of BRCA1 showed lack of methylation in all $31 \mathrm{PCa}$ cases. Two other loci on chromosome 17q (17q GRR and ERBB-2/HER-2) were analyzed to investigate whether BRCA1 alterations are limited to BRCA1 or caused by larger alterations of chromosome 17q. The BRCA1 gains were found restricted to the gene locus. On the contrary, BRCA1 losses coexisted in $71 \%$ of the cases with the loss of 17q GRR containing genes already proposed to be involved in tumorigenesis, e.g. BECN1, EZH1 and VPS25 (Fig. 1C)(19-21). Losses of the entire region of chromosome 17 encompassing bands q12-21.1 were detected in $3 \%$ of all cases. Nevertheless, only BRCA1 alterations correlated significantly with clinical parameters (Tab. S2). BRCA1 losses were associated with more advanced T status $(\mathrm{p}=0.014)$ and higher Gleason score determined in TCs $(\mathrm{p}=0.048)$. They occurred also more frequently in tumors with node-positive status $(\mathrm{p}=0.032)$, whereas BRCA1 gains were observed only in node-negative patients.

\section{Prognostic value of BRCA1 aberrations}

When compared to the BR data only BRCA1 losses classified according to the cut-off values $\leq 0.75$ indicated the patients with the shorter disease-free survival ( $p=0.0161$, Fig. $2 \mathrm{~A})$. In addition, BRCA1 losses appeared to be prognostically significant in multivariate analysis ( $p=0.048$, Fig. $2 \mathrm{~B}$ ). However, the Cox Regression model was done on a relatively small group of patients and needs to be confirmed on a larger cohort.

\section{BRCA1 aberrations in prostate cancer metastasis to pelvic lymph nodes and circulating tumor cells}

In LNM, losses were found in $27 \%$ of 62 evaluable cases and were significantly increased in comparison to primary tumors ( $\mathrm{p}=0.0072$ ). BRCA1 gains were detected at a frequency similar to primary $\mathrm{PCa}(8 \%)$. The comparison of corresponding pairs of primary tumors and its metastases revealed that 8 of 11 pairs exhibited the matching BRCA1 gene status in LNM and at least one tumor focus (Tab. 2). In this analysis TCs were compared as well as the larger sections of tumor and metastasis specimens which helped to determine the additional foci of tumor cells bearing BRCA1 aberrations within primary tumors. It confirmed the suspected transmission of genetic abnormalities between these two sites suggesting that somatic BRCA1 mutations can predispose cells to dissemination. As a proof of principle, BRCA1 gene dosage was also assessed in tumor cells separated from peripheral blood of 
PCa patients suffering from metastasis. The BRCA1 losses were found in cytokeratin (CK +)-and of note vimentin (Vim+)-positive CTCs isolated from peripheral blood (Fig. 3A, B). Applying the strategy in which the frequency of cells with BRCA1 losses was counted in 500 randomly selected cells and compared to the indices of false-hybridization obtained in the normal healthy volunteers, significantly elevated number of cells with BRCA1 loss were found in 4 of 7 patients $(\mathrm{p}<0.05)$. Of note is that both Vim staining and scoring method helped to point out the cells, particularly, when the pattern two BRCA1 copies : three CEP17 copies was observed (Fig. 3B). Such a genotype was rarely detectable in the blood of healthy volunteers. The clinically established parameters such as $\mathrm{T}$ and $\mathrm{N}$ status showed that the cells bearing BRCA1 losses in PCa seem to be efficient to penetrate LN, possibly survive the stress conditions in blood stream and consequently might invade distant organs.

\section{Determination of PTEN gene dosage}

Another tumor suppressor gene PTEN is reported to be lost in both primary PCa (22) and a majority of prostate CTCs (3) which is also believed to be one of the initiating neoplastic events during prostate tumorigenesis in mice (23). In the current study, PTEN gene dosage was analyzed in a fraction of PCa and LNM and compared with the status of BRCA1 gene. The AI of PTEN paralleled BRCA1 losses and gains, but was also found in cases with normal BRCA1 gene dosage both in 31 tested primary PCa and 11 corresponding pairs PCaLNM (Tab. 2, S3). This observation leads to the conclusion that PTEN losses always underlie BRCA1 losses but not vice versa.

\section{Discussion}

The high prevalence of prostate cancer in the male population needs accurate diagnostic tools early designating patients at risk of progression. The so-far used PSA screening copes with this challenge only partially (1), hence the characterization of new progression markers seem to be urgently required. In a previous study including 9 loci, it was found that a fraction of CTCs delivered from one, even very small focus, bears BRCA1 AIs and may be associated with early BR after radical prostatectomy (3). In order to evaluate the biological and clinical impact of this phenomenon, we performed FISH for BRCA1 on a larger cohort of PCa patients. The present results confirm the BRCA1 aberrations, particularly losses, and define their heterogeneity within different foci of the single tumor. This demonstrates the unique character of the cells carrying BRCA1 alterations, stays in agreement with the previous observations (3) and supports the hypothesis of monoclonal origin of $\mathrm{PCa}$ metastases (24).

Unlike in sporadic breast cancer where BRCA1 methylation is a frequent event (25), BRCA1 promoter was not methylated in any analyzed $\mathrm{PCa}$ sample including the ones with the detected BRCA1 loss or gain. It suggests that BRCA1 can be haploinsufficient as it was observed already in breast and ovarian cancer $(26,27)$.

In more than $70 \%$ of cases, a simultaneous loss of BRCA1 and the 17q GRR locus was observed. At this locus, at least 3 genes can hypothetically amplify the effect of BRCA1 loss: BECN1 involved in autophagy (19), EZH1 responsible for epigenetic processes (20) as well as VPS25 identified as a potential tumor suppressor in D. melanogaster (21). Nevertheless, only the distinct loss of BRCA1 was found to be related to poor clinicalpathological and early BR. Therefore, we applied BRCA1 FISH analysis on LNM and CTCs enriched from peripheral blood of metastatic PCa patients. The significantly increased frequency of BRCA1 loss in LNM and its high detection rate in LNM of the corresponding tissue pairs supports the hypothesis of a critical role of BRCA1 loss in dissemination of distinct subclones of PCa cells. 
The functional pathways of dissemination of PCa cells triggered by BRCA1 loss remains unclear and merit further investigation. The BRCA1 deficiency was already shown to mediate breast cancer cells migration $(28,29)$ and regulate some epithelial-mesenchymal transition (EMT)-associated proteins (28). It can be speculated that BRCA1 loss induces EMT processes in PCa. Intriguingly, in the current series standard immunofluorescent CK staining applied for CTCs detection underestimated the number of CTCs with BRCA1 loss. It could have been caused by the inability of the used antibody to recognize all types of CKs. However, in contrary to CK staining, the usage of EMT marker vimentin raised the detection rate of these cells. The application of vimentin might be controversial, but, indicated the cells with two copies of BRCA1 in the presence of three copies of CEP17 barely detected in blood of the healthy volunteers. It can complement CK staining and, hence, potentially extended the spectrum and yield of CTCs. Of note is, that increased vimentin expression had been reported in more aggressive types of $\mathrm{PCa}(30,31)$.

BRCA1 aberrations coincided with AI of the co-analyzed PTEN gene which stays in agreement with the previous observations in CTCs (3). The occurrence of PTEN AI without BRCA1 aberration supports the assumption that PTEN loss occurs as a 'first hit' in prostate tumorigenesis and a subsequent loss of BRCA1 can enhance its effect. It might be hypothesized that PTEN AI and other factors lead to an increased activation of the Akt pathway (32). As one option of explanation it might result in impairment of BRCA1- and RAD51-driven homologous recombination by retention of these proteins in the cytoplasm (33). One may speculate that defects of homologous recombination generate different chromosomal aberrations among others a loss of BRCA1, which promotes further tumorigenesis and triggers PCa dissemination (Fig. 4), e.g. in an EMT-mimicking way.

Our current results show that even a small population of cells bearing BRCA1 losses can be associated with $\mathrm{PCa}$ tumor cell dissemination potentially indicating those patients which are at high risk of metastasis. Further investigations should focus on the investigation of clinical relevance of this phenomenon on the large cohort of patients and definition of BRCA1related functional proteins involved in this process.

\section{Acknowledgments}

We thank all patients for their contribution to the study. The work of HUW was supported in parts by NIH grant CA123370 and a grant from the Director, Office of Energy Research, Office of Health and Environmental Research, U.S. Department of Energy, under contract DE-AC02-05CH11231. The ideogram of chromosome 17 on Fig. 1 was granted from David Adler (Department of Pathology, University of Washington, USA).

\section{Abbreviations}

$\begin{array}{ll}\text { 17q GRR } & \text { gene rich region located on 17q21 proximal of BRCA1 } \\ \text { AI } & \text { allelic imbalance } \\ \text { BR } & \text { biochemical recurrence } \\ \text { CEP17 } & \text { centromer 17 } \\ \text { CTC } & \text { circulating tumor cell } \\ \text { EMT } & \text { epithelial-mesenchymal transition } \\ \text { FFPE } & \text { formaline-fixed, paraffin embedded tissue } \\ \text { FISH } & \text { fluorescence in situ hybridization } \\ \text { MLPA } & \text { multiplex ligation-dependent probe amplification analysis }\end{array}$




$\begin{array}{ll}\text { LN } & \text { lymph node } \\ \text { LNM } & \text { lymph node metastasis } \\ \text { PCa } & \text { prostate cancer } \\ \text { PSA } & \text { prostate specific antigen } \\ \text { TC } & \text { tissue core } \\ \text { TMA } & \text { tissue microarray } \\ \text { TBST } & \text { Tris Buffered Saline/1\% Tween-20 }\end{array}$

\section{References}

1. Schröder FH, Hugosson J, Roobol MJ, et al. Screening and prostate-cancer mortality in a randomized European study. N Engl J Med 2009;360:1320-8. [PubMed: 19297566]

2. de Bono JS, Scher HI, Montgomery RB, et al. Circulating tumor cells predict survival benefit from treatment in metastatic castration-resistant prostate cancer. Clin Cancer Res 2008;14:6302-9. [PubMed: 18829513]

3. Schmidt H, DeAngelis G, Eltze E, Grockel I, Semjonow A, Brandt B. Asynchronous growth of prostate cancer is reflected by circulating tumor cells delivered from distinct, even small foci, harboring loss of heterozygosity of the PTEN gene. Cancer Res 2006;66:8959-65. [PubMed: 16982734]

4. Boulton S. Cellular functions of the BRCA tumour-suppressor proteins. Biochem Soc Trans 2006;34:633-45. [PubMed: 17052168]

5. Turner N, Tutt A, Ashworth A. Hallmarks of 'BRCAness' in sporadic cancers. Nat Rev Cancer 2004;4:814-9. [PubMed: 15510162]

6. Beger C, Ramadani M, Meyer S, et al. Down-regulation of BRCA1 in chronic pancreatitis and sporadic pancreatic adenocarcinoma. Clin Cancer Res 2004;10:3780-7. [PubMed: 15173085]

7. Grabsch H, Dattani M, Barker L, et al. Expression of DBA double-strand break repair proteins ATM and BRCA1 predicts survival in colorectal cancer. Clin Cancer Res 2006;12:1494-1500. [PubMed: 16533773]

8. Xing D, Scangas G, Nitta M, et al. A role for BRCA1 in uterine leiomyosarcoma. Cancer Res 2009;69:8231-5. [PubMed: 19843854]

9. Liede A, Karlan BY, Narod SA. Cancer risk for male carriers of germline mutations in BRCA1 or BRCA2: a review of the literature. J Clin Oncol 2004;4:735-42. [PubMed: 14966099]

10. Mitra A, Fisher C, Foster CS, et al. Prostate cancer in male BRCA1 and BRCA2 mutation carriers has a more aggressive phenotype. Br J Cancer 2008;98:502-7. [PubMed: 18182994]

11. Agalliu I, Gern R, Leanza S, Burk RD. Associations of high-grade prostate cancer with BRCA1 and BRCA2 founder mutations. Clin Cancer Res 2009;15:1112-20. [PubMed: 19188187]

12. Gao X, Zacharek A, Salkowski A, Grignon DJ, Sakr W, Porter AT, Honn KV. Loss of heterozygosity of the BRCA1 and other loci on chromosome 17q in human prostate cancer. Cancer Res 1995;55:1002-1005. [PubMed: 7866981]

13. Cheng L, Song S-Y, Pretlow TG, Abdul-Karim FW, Kung H-J, Dawson DV, Park W-S, Moon YW, Tsai M-L, Linehan WM, Emmert-Buck MR, Liotta LA, Zhuang Z. Evidence of independent origin of multiple tumours from patients with prostate cancer. J Natl Caner Inst 1998;90:233-237.

14. Uchida T, Wang C, Sato T, Gao J, Takashima R, Irie A, Ohori M, Koshiba K. BRCA1 gene mutation and loss of heterozygosity on chromosome 17q21 in primary prostate cancer. Int $\mathrm{J}$ Cancer 1999;84:19-23. [PubMed: 9988226]

15. Watanabe M, Shiraishi T, Muneyuki T, Nagi M, Fukutome K, Murata M, Kawamura J, Yatani R. Allelic loss and microsatellite instability in prostate cancers in Japan. Oncology 1998;55:569-574. [PubMed: 9778625]

16. Korsching E, Jeffrey SS, Meinerz W, Decker T, Boecker W, Buerger H. The origin of vimentin expression in invasive breast cancer: epithelial-mesenchymal transition, myoepithelial histogenesis 
or histogenesis from progenitor cells with bilinear differentiation potential? J Pathol 2005;206:451-7. [PubMed: 15906273]

17. Brandt B, Griwatz C. Two-layer buoyant density centrifugation gradient for enrichement of prostate-derived cells and cell clusters from peripheral blood. Clin Chem 1996;42:1881-2. [PubMed: 8906098]

18. Schouten JP, McElgunn CJ, Waaijer R, Zwijnenburg D, Diepvens F, Pals G. Relative quantification of 40 nucleic acid sequences by multiplex ligation-dependent probe amplification. Nucleic Acids Res 2002;30:e57. [PubMed: 12060695]

19. Yue Z, Jin S, Yang C, Levine AJ, Heintz N. Beclin 1, an autophagy gene essential for early embryonic development, is a haploinsufficient tumor suppressor. Proc Nat Acad Sci USA 2003;100:15077-82. [PubMed: 14657337]

20. Margueron R, Li G, Sarma K, et al. Ezh1 and Ezh2 maintain repressive chromatin through different mechanisms. Mol Cell 2008;32:503-18. [PubMed: 19026781]

21. Herz HM, Woodfield SE, Chen Z, Bolduc C, Bergmann A. Common and distinct properties of ESCRT-II components in Drosophila. PLoS One 2009;4:e4165. [PubMed: 19132102]

22. Yoshimoto M, Cunha IW, Coudry RA, et al. FISH analysis of 107 prostate cancers shown the PTEN genomic deletion is associated with poor clinical outcome. Br J Cancer 2007;97:678-85. [PubMed: 17700571]

23. Wang S, et al. Pten deletion leads to the expansion of a prostatic stem/progenitor cell subpopulation and tumor initiation. Proc Nat Acad Sci USA 2006;5:1480-5. [PubMed: 16432235]

24. Liu W, Laitinen S, Khan S, et al. Copy number analysis indicates monoclonal origin of lethal metastatic prostate cancer. Nat Med 2009;15:559-65. [PubMed: 19363497]

25. Xu X, Gammon MD, Zhang Y, et al. BRCA1 promoter methylation is associated with increased mortality among women with breast cancer. Breast Cancer Res Treat 2009;115:397-404. [PubMed: 18521744]

26. Press JZ, de Luca A, Boyd N, et al. Ovarian carcinomas with genetic and epigenetic BRCA1 loss have distinct molecular abnormalities. BMC Cancer 2008;8:17. [PubMed: 18208621]

27. Staff S, Isola J, Tanner M. Haplo-insufficiency of BRCA1 in sporadic breast cancer. Cancer Res 2003;63:4978-83. [PubMed: 12941823]

28. Yasmeen A, Liu W, Dekhil H, et al. BRCA1 mutations contribute to cell motility and invasion by affecting its main regulators. Cell Cycle 2008;23:3781-3. [PubMed: 19098453]

29. Promkan M, Liu G, Patmasiriwat P, Chakrabarty S. BRCA1 modulates malignant cell behaviour, the expression of surviving and chemosensitivity in human breast cancer cells. Int J Cancer 2009;125:2820-8. [PubMed: 19551867]

30. Lang SH, Hyde C, Reid IN, et al. Enhanced expression of vimentin in motile prostate cell lines and in poorly differentiated and metastatic prostate carcinoma. Prostate 2002;52:253-63. [PubMed: 12210485]

31. Zhao Y, Yan Q, Long X, Chen X, Wang Y. Vimentin affects the mobility and invasiveness of prostate cancer cells. Cell Biochem Funct 2008;26:571-7. [PubMed: 18464297]

32. Dubrovska A, Sungeun K, Salamone RJ, et al. The role of PTEN/Akt/PI3K signaling in the maintenance and viability of prostate cancer stem-like cell populations. Proc Nat Acad Sci USA 2009;106:268-73. [PubMed: 19116269]

33. Plo I, Laulier C, Gauthier L, Lebrun F, Calvo F, Lopez BS. AKT1 inhibits homologous recombination by inducing cytoplasmic retention of BRCA1 and RAD51. Cancer Res 2008;68:9404-12. [PubMed: 19010915] 


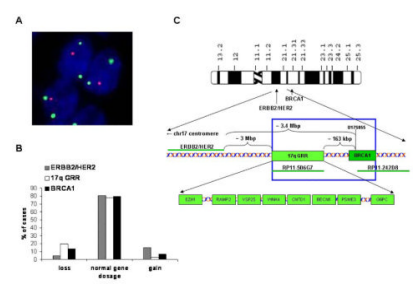

Figure 1.

A - BRCA1 loss in primary tumor: BRCA1 - Spectrum Orange, CEP17 - Spectrum Aqua displayed in green; magnification 1000x. B - The frequencies of ERB2/HER2, 17q GRR and BRCA1 loci losses, normal copy numbers or gains in 144, 149 and 133 patients informative for each locus. $\mathbf{C}$ - A simplified scheme of the DNA probes, genes and genetic distances within 17q12-21.1 investigated in this study. 


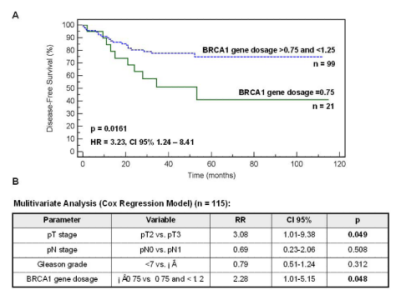

Figure 2.

A - Disease-free survival of prostate cancer patients with the BRCA1 gene dosage 0.75 vs. $>0.75$ and $\leq 1.25$. B - Multivariate analysis for the prognostic impact of $\mathrm{T}, \mathrm{N}$, Gleason score and BRCA1 gene dosage classifiers defined as shown in the table (Cox Regression Model). 
A
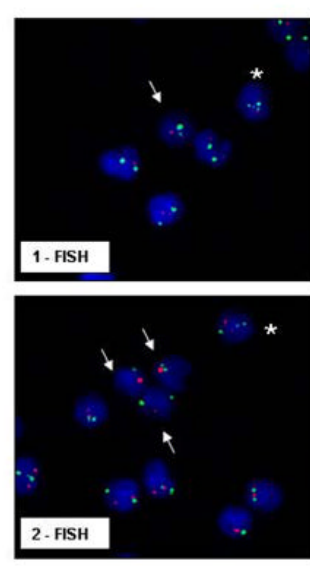
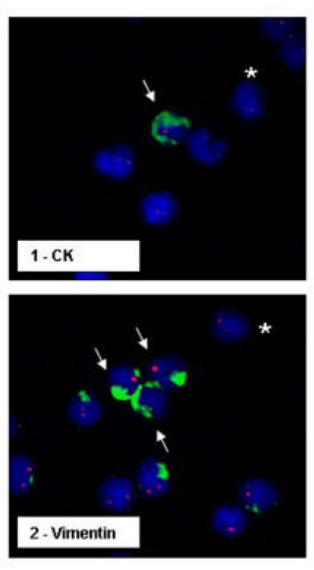

B

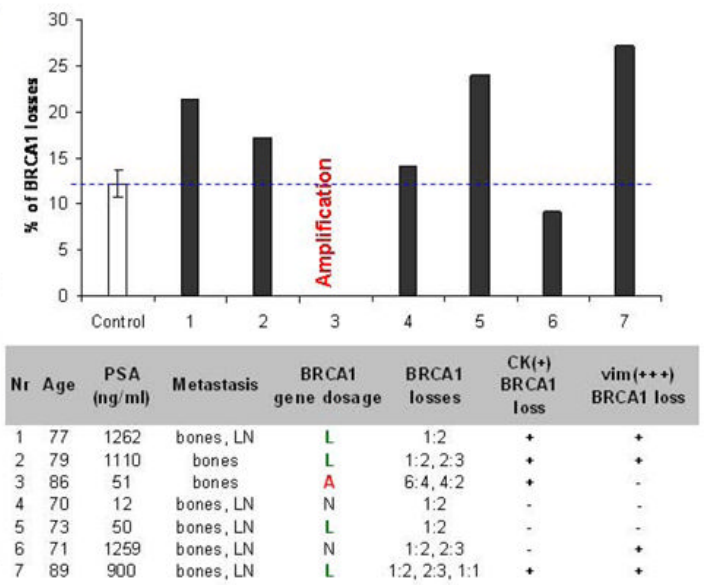

Figure 3.

Involvement of BRCA1 loss in PCa dissemination: A - CTCs with BRCA1 loss in metastatic PCa patients. Bar chart: Frequency (\%) of cells carrying BRCA1 loss in total 500 cells scored for BRCA1 gene dosage and compared to control (mean score for 3 healthy volunteers). Table: The presence of $\mathrm{CK}(+)$ and vim(+++) cells and the most frequently observed type of aberration presented as a ratio of BRCA1 and CEP17 probes. $\mathbf{B}-$ The examples of CTCs carrying BRCA1 loss: BRCA1 - Spectrum Orange, CEP17 - Spectrum Aqua displayed in green, vimentin or CK staining displayed in green; magnification 630x; arrows indicate the BRCA1 loss found in vim(+++) or CK(+) CTCs, asterisks - in vim(-) or $\mathrm{CK}(-)$ cells. 


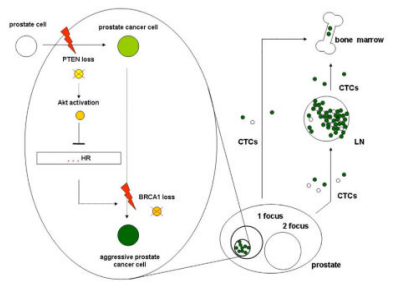

Figure 4.

A hypothetical model of the involvement of BRCA1 loss in prostate cancer dissemination and metastasis. 
Table 1

Clinical parameters of prostate cancer patients.

\begin{tabular}{c|c|c|c|}
\hline Clinical parameter & Status & $\mathbf{n}$ & $\%$ \\
\hline Age & $<65$ & 113 & 57 \\
& $\geq 65$ & 86 & 43 \\
\hline Focality & mono & 39 & 20 \\
& multi & 160 & 80 \\
\hline $\mathbf{T}$ & $2 \mathrm{a}$ & 18 & 9 \\
& $2 \mathrm{~b}$ & 12 & 6 \\
& $2 \mathrm{c}$ & 30 & 15 \\
& $3 \mathrm{a}$ & 99 & 50 \\
& $3 \mathrm{~b}$ & 39 & 20 \\
\hline $\mathbf{N}$ & $\mathrm{N} 0$ & 171 & 86 \\
& $\mathrm{~N} 1$ & 22 & 11 \\
\hline Gleason & $<7$ & 76 & 38 \\
& $\geq 7$ & 118 & 59 \\
\hline BR & $\mathrm{nBR}$ & 137 & 69 \\
& $\mathrm{BR}$ & 49 & 25 \\
\hline & &
\end{tabular}

Note: not all parameters are available for all 199 patients $\mathrm{n}$ - number of cases. 
Table 2

The BRCA1 gene dosage and PTEN AI in $11 \mathrm{PCa}$ - LNM pairs assessed in TMA and FFPE sections (WS).

\begin{tabular}{|c|c|c|c|c|c|}
\hline $\mathrm{Nr}$ & & $\begin{array}{l}\text { PTEN } \\
\text { (AI) }\end{array}$ & $\begin{array}{c}\text { TMA } \\
\text { (FISH) }\end{array}$ & $\begin{array}{l}\text { WS } \\
\text { (FISH) }\end{array}$ & $\begin{array}{c}\text { Final } \\
\text { BRCA1 status }\end{array}$ \\
\hline 1 & \begin{tabular}{|c|} 
Focus 1 \\
Focus 2 \\
Metastasis \\
\end{tabular} & $\begin{array}{l}0 \\
- \\
-\end{array}$ & $\begin{array}{l}\mathrm{L} \\
- \\
\mathrm{L}\end{array}$ & $\begin{array}{l}\mathrm{L} \\
\mathrm{L} \\
\mathrm{L}\end{array}$ & $\begin{array}{l}\mathrm{L} \\
\mathrm{L} \\
\mathrm{L}\end{array}$ \\
\hline 2 & \begin{tabular}{|c|} 
Focus 1 \\
Focus 2 \\
Metastasis \\
\end{tabular} & $\begin{array}{l}- \\
- \\
-\end{array}$ & $\begin{array}{l}\mathrm{L} \\
\mathrm{N} \\
\mathrm{L}\end{array}$ & $\begin{array}{l}L \\
L \\
L\end{array}$ & $\begin{array}{l}\mathrm{L} \\
\mathrm{L} \\
\mathrm{L}\end{array}$ \\
\hline 3 & \begin{tabular}{|c|} 
Focus 1 \\
Focus 2 \\
Metastasis \\
\end{tabular} & $\begin{array}{l} \\
\bullet \\
-\end{array}$ & $\begin{array}{l}\mathrm{N} \\
\mathrm{N} \\
\mathrm{L}\end{array}$ & $\begin{array}{l}\mathrm{N} \\
\mathrm{L} \\
\mathrm{L}\end{array}$ & $\begin{array}{l}\mathrm{N} \\
\mathrm{L} \\
\mathrm{L}\end{array}$ \\
\hline 4 & \begin{tabular}{|c|} 
Focus 1 \\
Focus 2 \\
Metastasis
\end{tabular} & : & $\begin{array}{l}N \\
N \\
-\end{array}$ & $\begin{array}{l}\mathrm{N} \\
\mathrm{N} \\
\mathrm{L}\end{array}$ & $\begin{array}{l}N \\
N \\
L\end{array}$ \\
\hline 5 & \begin{tabular}{|c|} 
Focus 1 \\
Focus 2 \\
Metastasis
\end{tabular} & $\begin{array}{l}-\dot{ } \\
- \\
-\end{array}$ & $\begin{array}{l}\mathrm{L} \\
\mathrm{N} \\
\mathrm{L}\end{array}$ & $\begin{array}{l}\mathrm{L} \\
\mathrm{L} \\
\mathrm{L}\end{array}$ & $\begin{array}{l}\mathrm{L} \\
\mathrm{L} \\
\mathrm{L}\end{array}$ \\
\hline 6 & \begin{tabular}{|c|} 
Focus 1 \\
Focus 2 \\
Metastasis
\end{tabular} & $\begin{array}{l}- \\
\\
\end{array}$ & $\begin{array}{l}N \\
N \\
-\end{array}$ & $\begin{array}{l}\mathbf{G} \\
\mathbf{G} \\
\mathrm{N}\end{array}$ & $\begin{array}{l}\mathbf{G} \\
\mathbf{G} \\
\mathrm{N}\end{array}$ \\
\hline 7 & \begin{tabular}{|c|} 
Focus 1 \\
Focus 2 \\
Metastasis \\
\end{tabular} & $\begin{array}{l}- \\
- \\
\end{array}$ & $\begin{array}{l}N \\
N \\
L\end{array}$ & $\begin{array}{l}\mathrm{N} \\
\mathrm{N} \\
\mathrm{N}\end{array}$ & $\begin{array}{l}N \\
N \\
L\end{array}$ \\
\hline 8 & \begin{tabular}{|c|} 
Focus 1 \\
Focus 2 \\
Metastasis
\end{tabular} & $\begin{array}{l}\bullet \\
- \\
-\end{array}$ & $\begin{array}{l}\mathrm{N} \\
- \\
\mathrm{L}\end{array}$ & $\begin{array}{l}- \\
- \\
-\end{array}$ & $\begin{array}{l}N \\
- \\
L\end{array}$ \\
\hline 9 & \begin{tabular}{|c|} 
Focus 1 \\
Focus 2 \\
Metastasis
\end{tabular} & $\begin{array}{l} \\
- \\
-\end{array}$ & $\begin{array}{l}- \\
\text { L }\end{array}$ & $\begin{array}{l}\mathrm{L} \\
\mathrm{L} \\
\mathrm{L}\end{array}$ & $\begin{array}{l}\mathrm{L} \\
\mathrm{L} \\
\mathrm{L}\end{array}$ \\
\hline 10 & \begin{tabular}{|c|} 
Focus 1 \\
Focus 2 \\
Metastasis
\end{tabular} & : & $\begin{array}{l}\mathrm{N} \\
\mathrm{N} \\
\mathrm{N}\end{array}$ & $\begin{array}{l}\mathrm{L} \\
\mathrm{L} \\
\mathrm{L}\end{array}$ & $\begin{array}{l}\mathrm{L} \\
\mathrm{L} \\
\mathrm{L}\end{array}$ \\
\hline 11 & \begin{tabular}{|c|} 
Focus 1 \\
Focus 2 \\
Metastasis
\end{tabular} & $\begin{array}{l}0 \\
- \\
-\end{array}$ & $\begin{array}{l}\mathrm{N} \\
\mathrm{N} \\
\mathrm{N}\end{array}$ & $\begin{array}{l}\mathbf{G} \\
\mathbf{G} \\
-\end{array}$ & $\begin{array}{l}\mathbf{G} \\
\mathbf{G} \\
\mathrm{N}\end{array}$ \\
\hline & & & & & $8 / 11 \mathrm{~L}$ \\
\hline
\end{tabular}

$\mathrm{L}$ indicates loss,

$\mathrm{N}$ - normal gene copy number,

G - gain,

Al - allelic imbalance analysis,

- allelic imbalance,

o- normal heterozygote

WS - whole section. 